\title{
Guy Groux, Jean-Marie Pernot, La grève
}

\section{Alexander Carlier}

\section{OpenEdition}

Journals

Édition électronique

URL : http://journals.openedition.org/travailemploi/3951

DOI : 10.4000/travailemploi.3951

ISSN : $1775-416 \mathrm{X}$

\section{Éditeur}

DARES - Ministère du Travail

\section{Édition imprimée}

Date de publication : 15 juin 2008

Pagination : 89-90

ISSN : 0224-4365

\section{Référence électronique}

Alexander Carlier, « Guy Groux, Jean-Marie Pernot, La grève », Travail et Emploi [En ligne], 114 | avril-juin 2008, mis en ligne le 05 novembre 2010, consulté le 09 avril 2021. URL : http://

journals.openedition.org/travailemploi/3951 ; DOI : https://doi.org/10.4000/travailemploi.3951 


\section{La Grève}

\section{Guy GROUX, Jean-Marie PERNOT}

\author{
Paris, Presses de la Fondation nationale des \\ Sciences politiques, 2008
}

\section{Lu par Alexander Carlier(**)}

À l'heure du quarantième anniversaire de mai 1968, la collection «Contester» propose d'analyser les différents modes de l'action collective. L'ouvrage de Guy Groux et Jean-Marie Pernot porte sur la grève, pratique souvent disqualifiée aujourd'hui comme archaiqque, inefficace, qui plus est en déclin si l'on en juge par la baisse continue du nombre de journées de grève depuis les années 1980. Les auteurs entendent au contraire dépasser la thèse de la mort de la grève et, plus généralement, celle de la fin du conflit dans le monde du travail.

\section{Réforme ou révolution?}

$\mathrm{Au} \mathrm{XIX}^{\mathrm{e}}$ siècle - et jusqu'aux premières décennies du $X^{\mathrm{e}}$ siècle - la grève est pour les ouvriers un moment de rupture avec la société. Pourtant, malgré la référence persistante à la "grève générale» dans le syndicalisme français, la grève devient progressivement un instrument de régulation du système capitaliste qui trouve sa pleine expression dans le compromis fordien des Trente Glorieuses. Le premier chapitre montre ce lent cheminement de la grève rebelle à la grève institution. La périodisation en trois étapes de Stéphane Sirot est ici reprise. La première période est celle de l'interdiction et de la répression (parfois sanglante) des coalitions ouvrières. La grève, acte de rébellion face au patron tout-puissant dans son entreprise, est originellement une réaction collective contre les excès de la concurrence capitaliste. Par la coalition, les ouvriers tentent de contrer les effets néfastes de la compétition entre les travailleurs. Les premiers syndicats visent à instaurer une «règle commune» d'emploi plus favorable pour les travailleurs. Avec la reconnaissance légale des coalitions ouvrières en 1864, commence l'âge de l'intégration du monde ouvrier au sein de la société. L'après 1945 est l'âge de l'institutionnalisation de la grève, dans un système de relations professionnelles où l'acteur syndical est pleinement reconnu et où l'État joue un rôle d'arbitre.

La grève dépasse ainsi peu à peu le cadre des solidarités locales et de métiers pour devenir un instrument de construction des droits sociaux, en même temps qu'elle s'appuie sur le droit et les conventions. De ce point de vue, les «nouveaux mouvements sociaux «(mal logés, sans papiers...) semblent aux yeux des auteurs moins originales qu'on pourrait le

(**) Direction de l'animation de la recherche, des études et des statistiques, Dares, département des relations professionnelles et temps de travail. penser: ces mouvements réactivent en fait le lien classique entre grève et droit.

La période actuelle n'est plus celle de la conquête par la grève de nouveaux droits sociaux mais plutôt celle de leur défense. Les auteurs notent ainsi que le mouvement de 1995 a abouti à des compromis moins substantiels que ceux de 1968 et de 1936.

\section{Dimensions théoriques}

Dans un second chapitre particulièrement dense, sont abordées les différentes doctrines sur le rôle de la grève comme fait social, sa place dans le système économique et politique. Les théories économiques sur la grève et ses cycles ont été remises en cause parce que trop déterministes. En effet, les grèves peuvent être parfois déconnectées du contexte économique (J.-D. Reynaud). Pour John Kelly, un ensemble de facteurs, pas seulement économiques, entrent en jeu.

Au-delà des divergences et des différentes disciplines sur lesquelles ils s'appuient, les discours théoriques sur la grève sont finalement convergents sur un point essentiel. Ils se rattachent tous à l'idée de l'institutionnalisation de la grève. Ce concept est indissociable d'un contexte historique précis, celui des Trente Glorieuses, qui combine plein emploi et rôle important de l'État dans l'économie et les relations professionnelles. De fait, le déclin des théories de la grève est lié au déclin de la grève comme outil du compromis fordiste.

En France comme en Europe, les conflits du travail ne se réduisent pas à la grève

En France, les statistiques enregistrent une baisse importante des grèves depuis un quart de siècle. Ce recul reflète celui de l'emploi industriel même si les usines demeurent les principaux lieux de la grève dans le secteur concurrentiel. De nouveaux espaces sont apparus: la fonction publique et les services publics ont pris une part croissante dans la conflictualité française. Cependant, l'instrument statistique sur lequel se fonde le constat du déclin de la grève est dépassé pour rendre compte de la conflictualité sociale contemporaine. Le décompte des journées de grève correspond en effet à une représentation datée de la grève franche de 24 heures dont les années 1945-1975 constituent «l'âge d'or». Car la grève n'est plus aussi centrale qu'auparavant. Elle s'inscrit dans un «halo de pratiques conflictuelles» qui sont mal (débrayages) ou pas recensées par la statistique (manifestations, pétitions, refus d'heures supplémentaires, etc.). Les enquêtes «Réponse» indiquent même une croissance et une diversification des conflits collectifs entre les années 1996-1998 et 2002-2004. La grève n'est plus aussi «représentative » du conflit qu'auparavant : on assiste à un redéploiement des modes d'action collective.

On aurait aimé à ce propos que l'ouvrage traite davantage, en y consacrant un développement distinct, la question de la nouveauté ou du retour de ces pratiques entourant la grève «classique». Comme les auteurs le font eux-mêmes remarquer, les défilés, les débrayages et les pétitions existent 
déjà à l'époque précédente. Il s'agit aujourd'hui donc plutôt d'une réactivation de modalités qui accompagnent ou se substituent à la grève. On assiste certes à des stratégies d'évitement de la grève, cette dernière n'étant plus au centre des pratiques comme des discours de la plupart des syndicats. Mais on peut également observer que la grève n'a pas dit son dernier mot, réapparaissant dans des secteurs où on l'attendait pas (commerce, restauration rapide). D'ailleurs, les auteurs notent prudemment qu'il est trop tôt pour savoir si les tendances récentes dessinent un "nouveau paradigme de l'action collective».

Les revendications ont également changé avec la montée d'un chômage de masse dans les années 1980: c'est moins les conditions de travail que la défense de l'emploi qui devient l'enjeu primordial des luttes.

Cette défense de l'emploi ne peut plus se faire seulement au niveau national car les décisions des entreprises se prennent de plus en plus en dehors de ce cadre. En dépit de quelques mouvements marquants (chauffeurs routiers en 1998), le développement de grèves européennes se heurte à de nombreux obstacles. Les solidarités transnationales sont difficiles à construire, notamment quand, à l'intérieur même de l'Europe, une délocalisation décriée ici est synonyme d'emploi là-bas.

Les auteurs montrent en particulier que les différences des droits nationaux en matière de droit de grève constituent un obstacle redoutable pour la grève européenne. Car aucun droit de grève européen n'a encore réussi à émerger, et cette question reste pour le moment une «chasse gardée» de chacun des États membres de l'Union. Qu'il s'agisse de la reconnaissance ou non des grèves politiques, de l'intervention des tribunaux ou de la possibilité pour l'employeur de recourir au lock-out (GrandeBretagne), les législations nationales déploient des dispositifs d'encadrement de la grève plus ou moins restrictifs. Les limitations importantes au droit de grève dans certains pays rendent d'ailleurs les comparaisons entre pays européens en termes de nombre de jours de grève peu pertinentes. Cet indicateur statistique ne rend pas compte en outre des stratégies de contournement de la grève que les salariés peuvent mettre en œuvre pour protester (absentéisme, freinage de la production, etc.).

Malgré les limites de cet exercice de comparaison, on constate que la France partage avec les autres pays européens le recul des grèves sur longue période. Si le secteur public et les transports contribuent plus qu'ailleurs à la conflictualité, la France n'apparaît pas comme un pays particulièrement gréviste. D'ailleurs, à rebours des idées reçues, les auteurs soulignent que certains pays connus pour leurs relations professionnelles peu conflictuelles ont récemment vécu une résurgence des grèves (Allemagne, Autriche, Danemark).
Dans leur conclusion, les auteurs dégagent notamment trois tendances qui marquent l'évolution de la grève aujourd'hui, en France comme ailleurs. Dans un contexte de chômage massif, on assiste à un retour de la concurrence entre les salariés. Face à l'éclatement des collectifs de travail, à l'individualisation croissante de la relation salariale, et à la compétition économique internationale, il est plus difficile de mobiliser les salariés dans un mouvement de grève dont l'efficacité est incertaine. Par rapport aux grandes mobilisations d'hier, les grèves d'aujourd'hui se replient sur des enjeux immédiats et locaux, internes à l'entreprise voire infra entreprise (on peut ajouter à ce propos que cette évolution va de pair avec le mouvement de décentralisation de la négociation collective au niveau de l'entreprise, au détriment de la négociation de branche ou interprofessionnelle). Les objectifs des conflits actuels sont également limités: ils ne remettent pas en cause l'organisation de la société mais cherchent désormais à obtenir de maigres compensations.

Cet ouvrage fournit une synthèse réussie et intellectuellement stimulante, en 140 pages denses mais toujours accessibles. Pour les auteurs, «l'esprit de résistance» passe de plus en plus par d'autres canaux que la grève au sein des entreprises.

On peut néanmoins ajouter que la grève, peutêtre justement parce qu'elle est plus exceptionnelle aujourd'hui qu'hier, demeure un moment de (re)construction des collectifs de travail. Les salariés qui cessent le travail partagent en effet une expérience forte, mêlant les sentiments de transgression, de liberté et de fierté. De ce point de vue, la grève est toujours un temps particulier de rupture et de prise de parole pour le monde du travail. 